\title{
ANÁLISE TEMPORAL DA FLORA NATIVA NO ENTORNO DE UNIDADES DE CONSERVAÇÃO - APA CACHOEIRA DAS ANDORINHAS E FLOE UAIMII, OURO PRETO, MG ${ }^{1}$
}

\author{
Renato Andrade Rezende ${ }^{2}$, José Francisco do Prado Filho ${ }^{3}$ e Frederico Garcia Sobreira ${ }^{3}$
}

\begin{abstract}
RESUMO - A crescente fragmentação das paisagens tem contribuído para a perda da diversidade biológica nas diversas regiões brasileiras. Isso se deve, na grande maioria dos casos, à maneira desordenada com que o homem vem usando e ocupando as terras. A criação de áreas protegidas ou unidades de conservação (UC) tem sido um dos principais mecanismos utilizados para a proteção da biodiversidade (in situ), além de assumir objetivos mais amplos como a proteção dos recursos hídricos, de espécies ameaçadas, dos recursos genéticos, do grau de endemismo, dos habitats, entre outros. Contudo, é preciso que haja instrumentos de avaliação periódica do seu estado de conservação, visando fornecer subsídios aos planos de manejo através da identificação das potenciais ameaças à funcionalidade ecológica dessas áreas protegidas. Com base em mapas temáticos de classificação da cobertura do solo, elaborados para os anos de 1989 e 2008, no intuito de analisar as alterações ocorridas na área de estudo neste mesmo período, este trabalho quantificou a dinâmica da flora nativa no interior e entorno da Área de Proteção Ambiental Estadual Cachoeira das Andorinhas e da Floresta Estadual do Uaimii, localizadas no Município de Ouro Preto (MG). Os resultados mostram que, ao longo dos 19 anos de comparação, a área ocupada pela flora nativa manteve-se praticamente a mesma, com índices de 82 a 83\% no interior das UCs e 74\% no seu entorno. Com os resultados da fragmentação, torna-se possível identificar as áreas mais críticas ou sujeitas a maior pressão antrópica e direcionar programas específicos, no âmbito gerencial, para minimizá-los.
\end{abstract}

Palavras-chave: Unidades de conservação, Fragmentação e Zona de amortecimento.

\section{TEMPORARY ANALYSIS OF THE NATIVE FLORA IN THE SURROUNDINGS OF CONSERVATION UNITS - APA CACHOEIRA DAS ANDORINHAS AND FLOE UAIMII, OURO PRETO - MG}

\begin{abstract}
The increasing fragmentation of the landscapes has contributed for the loss of the biological diversity in many Brazilian regions. In most cases, this is due to the disordered manner in which man has been using and occupying lands. The creation of protected areas or conservation units (UC) has been one of the main mechanisms used for the protection of biodiversity (in situ), in addition to commit wider objectives as for example the protection of the hydro resources, of threatened species, genetic resources, degree of endemism, habitats, among others. However, it is necessary the existence of periodic evaluation tools of its conservation status aiming at suppling subsidies to management plans by identifying the potential threats to the ecological functionality of these protected areas. Based on thematic maps of soil cover classification, elaborated for the years 1989 to 2008, with the purpose of analyzing the changes in the study area in this very period, the present work quantified the dynamics of the native flora in the interior and surroundings of the Área de Proteção Ambiental Estadual Cachoeira das Andorinhas and Floresta Estadual do Uaimii, located in Ouro Preto (MG). The results show that throughout the 19 years of comparison, the area occupied by the native flora remained the same with indices of 82 to $83 \%$ inside the UCs and $74 \%$ in its surroundings. With the results of the fragmentation, it is possible to identify the most critical areas or the greatest anthropic pressure and to direct specific programs, in the management scope, to minimize them.
\end{abstract}

Keywords: Units of conservation, Fragmentation and Zone of damping.

\footnotetext{
${ }^{1}$ Recebido em 19.02.2009 e aceito para publicação em 14.04.2011.

${ }^{2}$ Instituto Federal Minas Gerais, IFMG Ouro Preto, Brasil. E-mail: <renato.andrade@ifmg.edu.br>.

${ }^{3}$ Universidade Federal de Ouro Preto, UFOP, Brasil. E-mail: <jfprado@depro.em.ufop.br> e <sobreira@degeo.ufop.br>.
} 


\section{INTRODUÇÃO}

O uso e a ocupação das terras de maneira desordenada, seja por atividades agropecuárias, seja por exploração de recursos naturais, ou ocupação urbana, de modo geral, resultam em processos de perda e fragmentação de habitats, alterando diversos processos biológicos e fragilizando ecossistemas com consequências que implicam perdas na diversidade biológica. Apesar de existir naturalmente, a fragmentação da paisagem tem-se intensificado pela ação humana.

A fragmentação florestal é um fenômeno global e está presente em quase todos os biomas. Suas consequências são particularmente graves, apesar de não serem valoradas adequadamente, por afetarem a estrutura e dinâmica dos ecossistemas, influenciando de modo negativo a diversidade biológica e a sustentabilidade de animais e plantas (VIANA; PINHEIRO, 1998; VIANA et al., 1992). Para Cerqueira et al. (2005), muitos habitats naturais, quase contínuos, são transformados em paisagens compostas por manchas isoladas do habitat natural, tornando-se a mais profunda alteração causada pelo homem no meio ambiente.

Segundo Metzger (2001), medidas de planejamento ambiental como o levantamento do uso das terras é fundamental para o entendimento da forma com que o espaço está sendo ocupado pelo homem e para a compreensão da organização espacial da paisagem, visando à sustentabilidade ambiental, social e econômica.

Nesse contexto, as unidades de conservação ou áreas legalmente protegidas, estimadas como elos vitais no sistema de proteção à biodiversidade, necessitam de que o seu entorno, área diretamente influenciada pela ação humana, seja considerado em planejamento para que possa evitar o isolamento geográfico das UCs. Portanto, o conhecimento da dinâmica de ocupação do entorno das UCs constitui uma ferramenta útil para a adoção de medidas de manejo que evitem ou minimizem a pressão antrópica sobre as áreas protegidas, servindo como subsídio ao gerenciamento da unidade de conservação.

Com este objetivo, foram feitas análises temporais da flora nativa no interior e no entorno da Área de Proteção Ambiental Estadual da Cachoeira das Andorinhas (APA Cachoeira das Andorinhas) e da Floresta Estadual do Uaimii (FLOE Uaimii) para verificar a sua dinâmica no período de 1989 a 2008.
Localizada em Ouro Preto (MG), porção meridional da Serra do Espinhaço, a região desperta grande interesse mínero-metalúrgico e histórico-cultural, além de ser considerada, segundo Drummond et al. (2005), de importância biológica “especial e extrema”, devido ao endemismo de anfíbios e plantas, alta riqueza de vertebrados, alta riqueza de espécies de aves raras, endêmicas e ameaçadas de extinção e ambiente único no Estado por seus campos ferruginosos.

\section{MATERIAL E MÉTODOS}

\section{1. Área de Estudo}

A APA Cachoeira das Andorinhas foi criada pelo Decreto Estadual N³0.264, de 16/10/1989, com área de 18.700 ha, considerando que esta área constitui patrimônio natural de reconhecido valor histórico, cultural, paisagístico, turístico e de rara beleza cênica, emoldurando o entorno histórico da cidade de Ouro Preto. Abrange o Distrito de São Bartolomeu, cujo povoamento remonta ao final do século XVII, como ponto de passagem das bandeiras paulistas. Está situada na bacia hidrográfica do Rio das Velhas, na qual possui nascentes que dão origem a este importante manancial de captação de água do sistema de abastecimento da Região Metropolitana de Belo Horizonte.

Em razão de sua situação diferenciada de outras áreas protegidas, em 2003, foi criada a FLOE Uaimii nos domínios da APA Cachoeira das Andorinhas (Decreto Estadual S/No de 21/10/2003), com área de 4.398 ha e com a finalidade de fomentar o uso sustentável dos recursos florestais e a pesquisa científica com ênfase em métodos para exploração sustentável de florestas nativas. A Figura 1 mostra a localização das unidades de conservação, destacando-se o contorno de influência delimitado para este trabalho.

Tanto a APA Cachoeira das Andorinhas quanto a FLOE Uaimii são classificadas como unidades de conservação de uso sustentável, sendo constituídas por terras públicas e privadas e Zoneamento EcológicoEconômico (ZEE), mas ainda carecendo de Plano de Manejo. Ambas contam com gerenciamento local (Instituto Estadual de Florestas - IEF) e Conselho Consultivo conjunto.

A região de estudo está inserida no Domínio da Floresta Atlântica com predominância fitofisionômica da floresta estacional semidecidual, campo limpo e sujo 


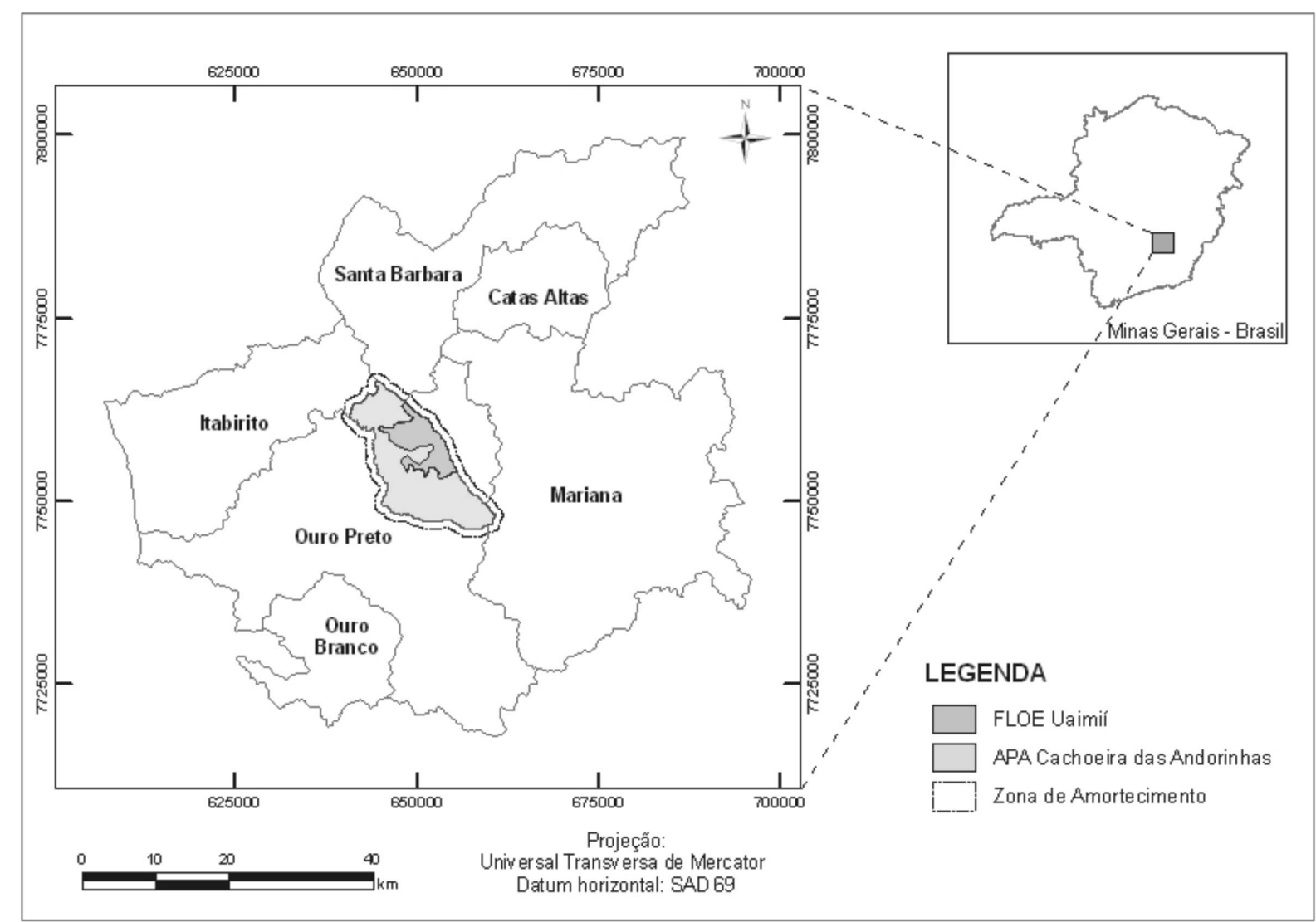

Figura 1 - Localização da APA Cachoeira das Andorinhas e FLOE Uaimii no Estado de Minas Gerais, Brasil.

Figure 1 - Localization of the APA Cachoeira das Andorinhas and FLOE Uaimii in the State of Minas Gerais, Brasil.

e campo rupestre (SCOLFORO; CARVALHO, 2006). O clima é do tipo temperado-úmido, com inverno seco e verão quente e chuvoso, apresentando precipitação média anual em torno de 1.400 a 1.800 mm e temperatura anual média do ar entre $14^{\circ}$ e $22^{\circ} \mathrm{C}$ (FUNDAÇÃO JOÃO PINHEIRO, 1975; PEDRALLI et al., 2001).

De acordo com o relatório do Zoneamento Ecológico-Econômico da APA Cachoeira das Andorinhas, a estrutura econômica da APA se baseia na agricultura familiar. A maior parte das propriedades possui área menor que 20 hectares (CARVALHO et al., 2006). Machado (2001) relata que, após a criação da APA, o êxodo rural foi intensificado e o uso ilegal dos recursos naturais dentro da APA foi indiretamente favorecido, visto o aumento da restrição das atividades econômicas locais, principalmente a agropecuária e a extração minerária.
Com relação às áreas que circundam as unidades de conservação, é possível identificar algumas atividades antrópicas como potencial ameaça à sua proteção, destacando-se os incêndios constantes, a exploração agropecuária extensiva e com baixo nível tecnológico e a exploração mineral praticada, principalmente por grandes mineradoras, além das diversas implicações resultantes da proximidade da APA Cachoeira das Andorinhas com a área urbana de Ouro Preto.

\subsection{Delimitação da amostra e programas utilizados}

O Sistema Nacional de Unidades de Conservação - SNUC (Lei Federal n 9.985/2000) não define zona de amortecimento para áreas de uso sustentável, diferentemente do que acontece para áreas de proteção integral, para as quais a Resolução CONAMA 13/90 define como raio de $10 \mathrm{~km}$ a área de influência que 
deverá ter suas atividades licenciadas pelo órgão ambiental competente, visando à proteção dos ecossistemas. Sendo assim, o entorno das UCs de uso sustentável fica sujeito a ações antrópicas sem normas e restrições específicas, até a elaboração de seu Plano de Manejo, que então definirá a extensão da zona de amortecimento mais adequada.

Estabeleceu-se, para este trabalho, uma faixa de $1 \mathrm{~km}$ de extensão no entorno das UCs como critério para o monitoramento da fragmentação da flora nativa, com o objetivo de avaliar a dinâmica de uso e ocupação do solo em seus limites mais próximos. Assim, foram feitas quantificações das classes predominantes da flora nativa no interior das UCs e no entorno estabelecido entre 1989 e 2008.

A base cartográfica foi derivada dos arquivos digitais do IBGE e trabalhada em ambiente SIG, utilizando-se o programa ArcGIS ${ }^{\circledR}$, versão 9.0 (ESRI, 2004). Para a elaboração do mapa de cobertura do solo, foi utilizado o programa ENVI®, versão 4.4 (RSI, 2007) e imagens de sensoriamento remoto Landsat-5 TM (17/02/1989 e 07/05/2008) do Banco de Imagens da Divisão de Geração de Imagens do Instituto Nacional de Pesquisas Espaciais -DGI/INPE (INPE, 2008).

Com base na classificação das fisionomias vegetais do Estado de Minas Gerais (SCOLFORO; CARVALHO, 2006), foram definidas as classes que compõem o mapa de cobertura do solo da área de estudo, procurando-se separar as paisagens naturais ou em regeneração (fitofisionomias nativas) das paisagens modificadas por ações antrópicas, visando analisar a fragmentação ocorrida no período de 1989 a 2008. Assim, para a quantificação da fragmentação da flora nativa, foram definidas cinco classes de cobertura do solo: Classe Floresta Estacional Semidecidual, incluindo as matas estabelecidas e em regeneração; Classe Campo, incluindo os campos de altitude, campo limpo e campo sujo; Classe Campo Rupestre, distribuídos ao longo da cadeia do espinhaço; Classe Água, apesar de significativa na área de estudo, representa apenas os reservatórios ou açudes artificiais com área superior a $900 \mathrm{~m}^{2}$, tamanho do pixel das imagens de satélite utilizadas (Landsat-5 TM); Classe Outros, representando as classes com interferência antrópica (urbanização, agropecuária e mineração).

As imagens orbitais selecionadas através do catálogo de imagens da DGI/INPE (INPE, 2008) levaram em consideração a resposta espectral dos tipos vegetacionais e do solo dentro do período de análise (1989 a 2008), além da qualidade do arquivo e a presença de nuvens sobre a área de interesse. O georreferenciamento das imagens foi feito com base nos arquivos vetoriais elaborados no ArcGIS (shapefile da área de estudo e das UCs) e importados para o ENVI. Após a alocação dos vetores, a área de estudo contendo as unidades de conservação e o buffer de $1 \mathrm{~km}$ de extensão foi recortada do arquivo original para redução da dimensionalidade, reduzindo o tamanho do arquivo e o tempo de processamento. Para efeito de classificação, foi utilizada a composição colorida TM7 (R), TM3 (G) e TM2 (B) para melhor identificação dos alvos terrestres e definição dos pixels coletados (FLORENZANO, 2002).

A metodologia utilizada para a classificação das imagens de sensoriamento remoto foi a supervisionada, e as amostras de treinamento, áreas representativas da imagem, foram coletadas em diversos pontos da área de estudo com auxílio de GPS, contemplando as classes que compõem o mapa para a determinação dos respectivos padrões ou assinaturas espectrais. Com base no prévio conhecimento da área de estudo, buscou-se delimitar amostras de treinamento homogêneas, chamadas de regiões de interesse, que foram avaliadas estatisticamente por histogramas, disponíveis no programa ENVI, que fornecem o perfil do espectro médio de cada banda para a região selecionada, tornando possível verificar a representatividade e qualidade das amostras. Os pixels coletados na região de interesse, área de treinamento, representam o comportamento médio das classes de cobertura do solo que foram submetidas à classificação.

O classificador utilizado para a obtenção do mapa de cobertura do solo foi o Support Vector Machine (SVM), que permite separar as classes através de uma superfície de decisão conhecida como hiperplano ideal, obtendo-se assim bons resultados de classificação. O SVM possui o parâmetro de penalidade que controla a concessão entre erros de treinamento permissíveis, gerando uma margem de tolerância entre as classes. Esta classificação possibilitou a geração de mapas de cobertura do solo para os anos de 1989 a 2008. O coeficiente Kappa (k) foi utilizado para avaliar a concordância entre a classificação do mapa temático produzido e a verdade terrestre, por meio de análise multivariada discreta, levando-se em consideração a matriz de confusão 
ou de erros. Esse procedimento é gerado no próprio programa de tratamento de imagem (ENVI) e possibilita a identificação dos erros de omissão e comissão. Tal estimativa é feita pelo confronto entre o resultado da classificação e a informação que contém a verdade terrestre (LANDIS; KOCH, 1977; CONGALTON et al., 1983; PONZONI; ALMEIDA, 1996).

A determinação do número de pontos para a verificação da verdade terrestre foi baseada na amostragem estratificada ao acaso, sendo considerado um percentual de exatidão de $90 \%$ e um erro permissível de 5\% (ANDERSON, 1971; BRITES et al., 1996). Após a elaboração dos mapas e visando ao cotejo dos resultados com a realidade, a área foi percorrida para avaliação das verdades terrestres com auxílio da conexão ENVI Link-GPS, que permite a leitura de dados diretamente do receptor GPS no display de visualização da imagem.

a) Mapa 1989

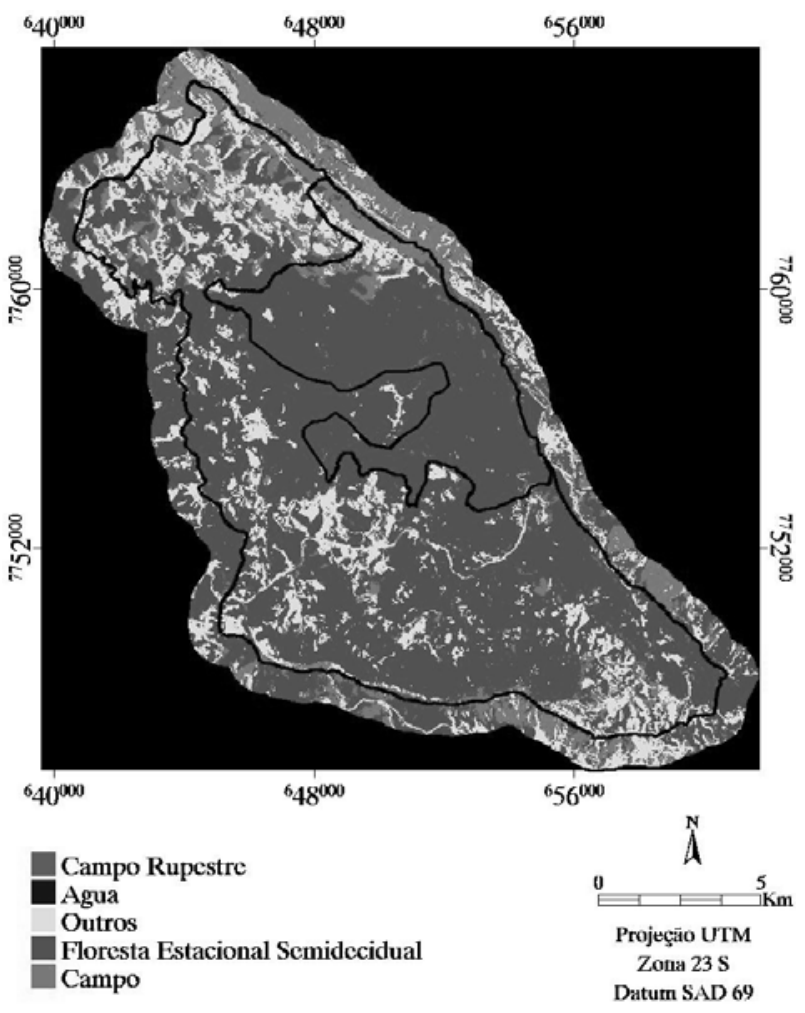

\section{RESULTADOS}

\subsection{Análise temporal do cenário da cobertura do solo de 1989 a 2008}

Os mapas temporais de cobertura do solo das unidades de conservação (Figura 2) cobrem uma área total aproximada de 25.755 hectares, incluindo a zona de amortecimento estabelecida para o trabalho, cuja área é de 7.055 hectares. A composição das classes temáticas para a APA como um todo e para a FLOE, separadamente, pode ser observada na Tabela 1.

A área ocupada com flora nativa (floresta estacional semidecidual, campo e campo rupestre) na APA como um todo passou de 82,96\% em 1989 para 82,22\% em 2008, e na FLOE, analisada isoladamente, a variação foi de 95,27\% em 1989 para 97,98\% em 2008.

A composição temática da flora nativa na zona de amortecimento, estabelecida para as UCs, pode ser observada na Tabela 2 .

b) Mapa 2008

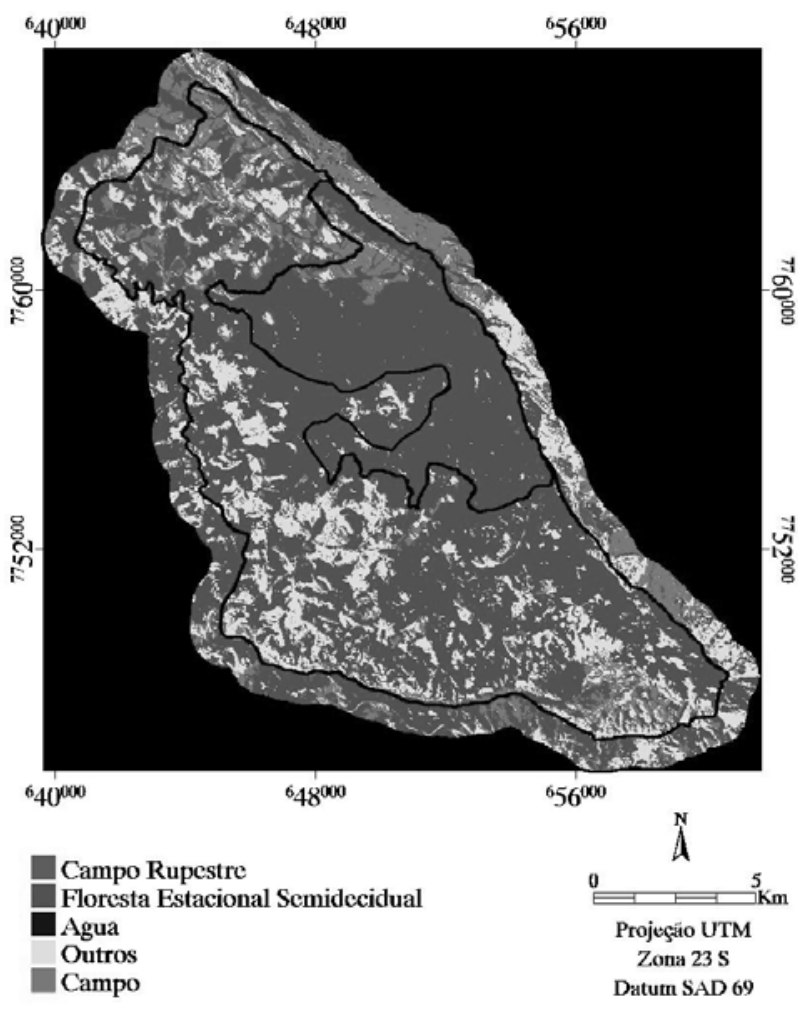

Figura 2 - Mapa de Cobertura do Solo das UCs e zona de amortecimento (1989 e 2008). Figure 2 - Map of Covering Ground of the UCs and Zone of Damping (1989 and 2008). 
Tabela 1 - Dinâmica da cobertura do solo no período de 1989 a 2008.

Table 1 - Dynamics of the covering ground in the period from 1989 to 2008.

\begin{tabular}{|c|c|c|c|c|c|c|c|c|}
\hline \multirow{4}{*}{$\begin{array}{l}\text { Classes de } \\
\text { cobertura } \\
\text { do solo }\end{array}$} & \multicolumn{4}{|c|}{1989} & \multicolumn{4}{|c|}{2008} \\
\hline & \multirow{2}{*}{\multicolumn{2}{|c|}{$\begin{array}{c}\text { APA Cachoeira das } \\
\text { Andorinhas } \\
\text { Área }\end{array}$}} & \multicolumn{2}{|c|}{ FLOE Uaimii } & \multicolumn{2}{|c|}{$\begin{array}{c}\text { APA Cachoeira das } \\
\text { Andorinhas }\end{array}$} & \multicolumn{2}{|c|}{ FLOE Uaimii } \\
\hline & & & & & & & & \\
\hline & $(\%)$ & (ha) & $(\%)$ & (ha) & $(\%)$ & (ha) & $(\%)$ & (ha) \\
\hline \multicolumn{9}{|l|}{ Floresta Est } \\
\hline Semidecidual & 72,60 & $13.576,20$ & 85,40 & $3.755,90$ & 70,27 & $13.140,49$ & 90,94 & $3.999,54$ \\
\hline Campo & 9,05 & $1.692,35$ & 9,20 & 404,62 & 11,00 & $2.057,00$ & 6,52 & 286,74 \\
\hline $\begin{array}{l}\text { Campo } \\
\text { Rupestre }\end{array}$ & 1,31 & 244,97 & 0,67 & 29,46 & 0,95 & 177,65 & 0,52 & 22,86 \\
\hline Outros & 17,04 & $3.186,48$ & 4,73 & 208,02 & 17,78 & $3.324,86$ & 2,02 & 88,86 \\
\hline Total & 100 & 18.700 & 100 & 4.398 & 100 & 18.700 & 100 & 4.398 \\
\hline
\end{tabular}

Tabela 2 - Dinâmica da flora nativa na zona de amortecimento, durante o período de 1989 a 2008. Table 2 - Dynamics of the native flora in the zone of damping during the period from 1989 to 2008.

\begin{tabular}{|c|c|c|c|c|}
\hline \multirow[t]{3}{*}{ Classes temáticas } & \multicolumn{2}{|c|}{1989} & \multicolumn{2}{|c|}{2008} \\
\hline & \multicolumn{2}{|c|}{ Zona de amortecimento } & \multicolumn{2}{|c|}{ Zona de amortecimento } \\
\hline & Área (\%) & Área (ha) & Área (\%) & Área (ha) \\
\hline Flora nativa & 74,68 & $5.274,40$ & 74,80 & $5.277,96$ \\
\hline Outros & 25,32 & $1.780,60$ & 25,20 & $1.777,04$ \\
\hline Total & 100 & 7.055 & 100 & 7.055 \\
\hline
\end{tabular}

\section{DISCUSSÕES}

Com relação aos valores obtidos sobre a exatidão da verdade terrestre (precisão global e coeficiente Kappa), pode-se afirmar que os mapas representam com segurança a paisagem da área de estudo, segundo as classes temáticas estabelecidas. A percentagem de acerto global para ambos os mapas foi superior ao valor mínimo aceitável (85\%), segundo Anderson (1971). A verificação da exatidão dos mapas de cobertura do solo dos anos de 1989 e 2008 pode ser observada nas Tabelas 3 e 4, que se constituem a matriz de confusão.

De acordo com a matriz de confusão do mapa de cobertura do solo de 1989 (Tabela 3), o maior erro de comissão foi encontrado na classe Outros, que incorporou amostras da classe Campo (23,52\%), sendo o acerto global de 92,95\% e o parâmetro Kappa de 0,91. A Tabela 4 mostra a matriz de confusão do mapa de cobertura do solo de 2008, sendo os maiores erros de comissão os seguintes: classe Florestal incluiu amostras da classe Campo (12,34\%); classe Campo incluiu amostras da classe Outros (9,37\%); classe Campo Rupestre incluiu amostras da classe Campo (4,25\%); classe Outros incluiu amostras da classe Campo (3,07\%). O acerto para o mapa de 2008 foi de 93,85\% e o parâmetro Kappa de 0,91.

A utilização das imagens Landsat-5 TM atende ao propósito de monitoramento da dinâmica da flora nativa no interior e entorno de unidades de conservação, possibilitando a utilização de imagens atualizadas e de domínio público, fornecidas pelo INPE. Dessa maneira, é possível gerar informações para subsidiar as ações contidas no Plano de Manejo das unidades de conservação ou até mesmo orientar a delimitação da área que deverá ser considerada como zona de amortecimento em UC de uso sustentável que ainda não tenham elaborado seu Plano de Manejo. No caso em que o objetivo seja caracterizar com mais detalhes a fitofisionomia ou as coleções hídricas, é aconselhável a utilização de imagens de sensoriamento remoto com maior resolução espacial.

A faixa delimitada para verificação da dinâmica da flora nativa, neste trabalho, pode ser utilizada como estratégia para uma rápida análise da integridade da

Revista Árvore, Viçosa-MG, v.35, n.3, p.435-443, 2011 
Tabela 3 - Matriz de confusão para o mapa de cobertura do solo (1989). Table 3 - Confusion matrix for the map of covering of the ground (1989).

\begin{tabular}{|c|c|c|c|c|c|c|}
\hline \multirow[t]{2}{*}{ Mapa Temático } & \multirow[b]{2}{*}{$\begin{array}{l}\text { Floresta Est. } \\
\text { Semidecidual }\end{array}$} & \multicolumn{4}{|c|}{ Verdade Terrestre } & \multirow[b]{2}{*}{ Tota } \\
\hline & & Campo & Campo Rupestre & Água & Outros & \\
\hline $\begin{array}{l}\text { Floresta Est. } \\
\text { Semidecidual }\end{array}$ & 54 & 0 & 0 & 0 & 0 & 54 \\
\hline Campo & 0 & 25 & 0 & 0 & 0 & 25 \\
\hline Campo Rupestre & 0 & 0 & 36 & 0 & 0 & 36 \\
\hline Água & 0 & 0 & 0 & 44 & 0 & 44 \\
\hline Outros & 0 & 16 & 0 & 0 & 52 & 68 \\
\hline
\end{tabular}

Tabela 4 - Matriz de confusão para o mapa de cobertura do solo (2008).

Table 4 - Confusion matrix for the map of covering of the ground (2008).

\begin{tabular}{|c|c|c|c|c|c|c|}
\hline \multirow[t]{2}{*}{ Mapa } & \multirow[b]{2}{*}{$\begin{array}{l}\text { Floresta Est. } \\
\text { Semidecidual }\end{array}$} & \multicolumn{4}{|c|}{ Verdade Terrestre } & \multirow[b]{2}{*}{ Total } \\
\hline & & Campo & Campo Rupestre & Água & Outros & \\
\hline Floresta Est. & 71 & 10 & 0 & 0 & 0 & 81 \\
\hline \multicolumn{7}{|l|}{ Semidecidual } \\
\hline Campo & 0 & 29 & 0 & 0 & 3 & 32 \\
\hline Campo Rupestre & 0 & 2 & 45 & 0 & 0 & 47 \\
\hline Água & 0 & 0 & 0 & 50 & 0 & 50 \\
\hline Outros & 0 & 4 & 0 & 0 & 126 & 130 \\
\hline
\end{tabular}

cobertura vegetal nativa nos limites adjacentes às UCs, visto que grande parte das zonas de amortecimento já é ocupada por diversas atividades potencialmente impactantes. Recomenda-se que a definição sobre a delimitação da zona de amortecimento em unidades de conservação leve em consideração uma análise mais complexa da paisagem onde está inserida, identificando-se os principais pontos de pressão para não se basear apenas na Resolução CONAMA 13/90, que define o raio de $10 \mathrm{~km}$ como área de influência para UC de proteção integral, com o objetivo de gerar um instrumento que realmente possibilite a sua aplicação em termos gerenciais e que a manutenção das áreas protegidas devidamente conectadas por habitats nativos.

Com relação à quantificação da flora nativa, percebe-se que, ao longo dos 19 anos de comparação, a área ocupada por flora nativa (floresta estacional semidecidual, campo limpo e sujo e campo rupestre) no interior da APA manteve-se praticamente a mesma, com índices em torno de 82 a $83 \%$. Considerando a FLOE Uaimii isoladamente, os índices de manutenção da flora nativa foram ainda melhores (96\%). Para o entorno delimitado como zona de amortecimento, os índices de manutenção da área ocupada com flora nativa ficaram próximos a 74\%. Apesar de a região ser rica em mananciais, a classe Água apresentou valores desprezíveis para a resolução das imagens Landsat-5 TM utilizadas.

Vários são os fatores que podem estar associados à privilegiada condição de conservação das unidades em estudo, destacando-se o histórico de ocupação da região onde as atividades carvoeiras, madeireiras e energéticas reservavam parte da floresta para manutenção de estoque (CARVALHO et al., 2006); a inexistência de grandes projetos agropecuários em virtude da ocupação da APA Cachoeira das Andorinhas ser caracterizada predominantemente por agricultura familiar; o abandono de áreas cultiváveis pela agricultura familiar devido à falta de incentivo e definição de diretrizes sustentáveis de uso da terra (inexistência de plano de manejo para a APA); a participação efetiva da gerência e do conselho consultivo destas UCs; importante apoio institucional do Instituto Estadual de Florestas (IEF - MG).

Com relação à efetividade do manejo, a APACachoeira das Andorinhas e a FLOE Uaimii destacam-se por possuírem o Zoneamento Ecológico-Econômico desde 
2006. Apesar de ainda não contarem com Plano de Manejo, as diretrizes estabelecidas no ZEE subsidiam as ações gerenciais para a sustentabilidade local. Segundo Dias et al. (2002), é fato conhecido o alto índice de unidades de conservação que ainda não possuem nenhum tipo de documentação técnica que auxilie a sua administração e preservação.

Lima et al (2005) apontam a falta de efetividade do manejo em unidades de conservação como um importante fator de contribuição na degradação dos ecossistemas, e a grande maioria das UCs de proteção integral em Minas Gerais apresentam nível insatisfatório de manejo.

\section{CONCLUSÕES}

A análise temporal da dinâmica da flora nativa, efetuada contínua e periodicamente, poderá ser utilizada como ferramenta para o monitoramento da cobertura do solo, no interior e principalmente no entorno de unidades de conservação, detectando possíveis degradações ambientais que possam comprometer a sua integridade. Além de se tratar de tecnologia já disponível no órgão responsável pela proteção florestal do Estado, com base nos dados levantados e nas análises realizadas, pode-se considerar:

- A classificação de imagens Landsat-5 TM com o propósito de monitorar a dinâmica da flora nativa, em UC e seu respectivo entorno, mostrou-se eficiente e de uso relativamente acessível.

- A análise da dinâmica da flora nativa pode ser indicada como instrumento auxiliar no gerenciamento de UC, que contenha Plano de Manejo ou que esteja em fase de elaboração, principalmente quanto ao estabelecimento da zona de amortecimento em UC de uso sustentável.

- Através dos resultados da quantificação temporal da flora nativa, é possível identificar as áreas mais críticas e direcionar programas específicos para minimizá-los no âmbito gerencial.

- Aárea que abriga a APA Cachoeira das Andorinhas, incluindo a FLOE Uaimii, manteve praticamente os mesmos índices de flora nativa, desde a sua criação em 1989. Os limites externos mais próximos das UCs também se mantiveram conservados.
- Torna-se urgente a elaboração do Plano de Manejo para as unidades de conservação em questão, com o propósito de contribuir para a manutenção da condição florestal encontrada.

\section{AGRADECIMENTOS}

À Fundação de Amparo à Pesquisa do Estado de Minas Gerais - FAPEMIG, ao Instituto Estadual de Florestas - IEF e ao Instituto Federal Minas Gerais.

\section{REFERÊNCIAS}

ANDERSON, J. R. Land use classification schemes used in selected recent geographic applications of remote sensing:

Photogrammetric Engineering \& Remote Sensing, v.37, n.4, p.379-387, 1971.

BRITES, R. S.; SOARES, V. P.; RIBEIRO, C. A. A. S. Efeitos da estratégia de amostragem na exatidão reportada pelo índice kappa na classificação de imagens orbitais. In: SIMPÓSIO BRASILEIRO DE SENSORIAMENTO REMOTO, 8., 1996, Salvador. Anais... São José dos Campos: INPE, SELPER, 1996. p.823-829.

CARVALHO, A. F. et al. Zoneamento ecológico-econômico da área de proteção ambiental cachoeira das andorinhas. Viçosa, MG: Universidade Federal de Viçosa, 2006.

CERQUEIRA, R. et al. Fragmentação: alguns conceitos. In: BRASIL.Ministério do Meio Ambiente. Fragmentação de ecossistemas: causas, efeitos sobre a biodiversidade e recomendações de políticas públicas. 2.ed. Brasília: 2005.p.23-40.

CONGALTON, R. G.; ODERWALD, R. G.; MEAD, R. A. Assessing Landsat Classification Accuracy Using Discrete Multivariate Analysis Statistical Techniques. Photogrammetric

Engineering \& Remote Sensing, v.49, n. 12, p.1671-1678, 1983.

DIAS, H. C. T. et al. Geoambientes do Parque Estadual do Ibitipoca, Município de Lima Duarte-MG. Revista Árvore, v.26, n.6, p.777-786, 2002. 
DRUMMOND, G. M. et al. Biodiversidade em Minas Gerais: um atlas para sua conservação. Belo Horizonte: Fundação Biodiversitas, 2005. 222p.

ENVIRONMENTAL SYSTEMS RESEARCH INSTITUTE - ESRI. Using ArcMap. Redlands: ESRI Press, 2004. 598p.

FUNDAÇÃO JOÃO PINHEIRO. Plano de Conservação, Valorização e Desenvolvimento de Ouro Preto e Mariana. Belo Horizonte: 1975.

INSTITUTO NACIONAL DE PESQUISAS ESPACIAIS - INPE. Catálogo de imagens. Disponível em: http://www.dgi.inpe.br. Acesso em: maio de 2008.

LANDIS, J. R.; KOCH, G. G. The measurement of observer agreement for categorial data.

Biometrics, v.33, n.1, p.159-174, 1977.

LIMA, G. S.; RIBEIRO, G. A.; GONÇALVES, W. Avaliação da efetividade de manejo das unidades de conservação de proteção integral em Minas Gerais. Revista Árvore, v.29, n.4, p.647-653, 2005.

MACHADO, C. A. P. Projeto de

implantação de infra-estrutura

turística de São Bartolomeu. Belo Horizonte: UFMG, 2001.118p.

METZGER, J. P. O que é ecologia de paisagens? Biota Neotropica, 2001. Disponível em: http:/ /www.biotaneotropica.org.br/vln12. Acesso em: nov. de 2007.
PEDRALLI, G.; GUIMARÃES NETO, A. S.; TEIXEIRA, M. C. B. Diversidade de anfíbios na região de Ouro Preto. Ciência Hoje, v.30, n.178, p.70-73, 2001.

PONZONI, J. F.; ALMEIDA, E. S. A estimativa do parâmetro Kappa (K) da análise multivariada discreta no contexto de um SIG. In: SIMPÓSIO BRASILEIRO DE SENSORIAMENTO REMOTO, 8., 1996, Salvador. Anais... São José dos Campos: INPE, SELPER, 1996. p.52-58.

RESEARCH SYSTEMS INC - RSI. ENVI 4.4 User's guide. Boulder: 2007.

SCOLFORO, J. R.; CARVALHO, L. M. T. Mapeamento e inventário da flora nativa e dos reflorestamentos de Minas Gerais. Lavras: Universidade Federal de Lavras, 2006.

VIANA, V. N.; PINHEIRO, L. A. F. V.

Conservação da biodiversidade em fragmentos florestais. Séria Técnica IPEF, v.12, n.32, p.25-42, 1998.

VIANA, V. N. et al. Restauração e manejo de fragmentos florestais. In: CONGRESSO NACIONAL SOBRE ESSÊNCIAS NATIVAS, 2., 1992, São Paulo. Anais... São Paulo: Instituto Florestal de São Paulo, 1992. p.400-407. 